\title{
GMR
}

\section{Dysregulation of TFDP1 and of the cell cycle pathway in high-grade glioblastoma multiforme: a bioinformatic analysis}

\author{
X. Lu' ${ }^{1}$, X.D. Lv ${ }^{1}$, Y.H. Ren ${ }^{1}$, W.D. Yang ${ }^{1}$, Z.B. Li ${ }^{1}$, L. Zhang ${ }^{1}$ and X.F. Bai ${ }^{2}$ \\ ${ }^{1}$ Department of Neurosurgery, Mudanjiang City Second People's Hospital, \\ Mudanjiang, China \\ ${ }^{2}$ Research Service Office, Mudanjiang City Second People's Hospital, \\ Mudanjiang, China \\ Corresponding author: X.F. Bai \\ E-mail: xuefengb2y@sina.com \\ Genet. Mol. Res. 15 (2): gmr.15027646 \\ Received September 16, 2015 \\ Accepted December 9, 2015 \\ Published June 10, 2016 \\ DOI http://dx.doi.org/10.4238/gmr.15027646
}

\begin{abstract}
Despite extensive research, the prognosis of high-grade glioblastoma multiforme (GBM) has improved only slightly because of the limited response to standard treatments. Recent advances (discoveries of molecular biomarkers) provide new opportunities for the treatment of GBM. The aim of the present study was to identify diagnostic biomarkers of high-grade GBM. First, we combined 3 microarray expression datasets to screen them for genes differentially expressed in patients with high-grade GBM relative to healthy subjects. Next, the target network was constructed via the empirical Bayesian coexpression approach, and centrality analysis and a molecular complex detection (MCODE) algorithm were performed to explore hub genes and functional modules. Finally, a validation test was conducted to verify the bioinformatic results. A total of 277 differentially expressed genes were identified according to the criteria $\mathrm{P}<0.05$ and $\mid \log _{2}$ (fold change) $\mid \geq 1$.5. These genes were most
\end{abstract}


significantly enriched in the cell cycle pathway. Centrality analysis uncovered 9 hub genes; among them, TFDP1 showed the highest degree of connectivity (43) and is a known participant in the cell cycle pathway; this finding pointed to the important role of TFDP 1 in the progression of high-grade GBM. Experimental validation mostly supported the bioinformatic results. According to our study results, the gene TFDP1 and the cell cycle pathway are strongly associated with high-grade GBM; this result may provide new insights into the pathogenesis of GBM.

Key words: Glioblastoma multiforme; Bioinformatics; Centrality analysis; Coexpression network

\section{INTRODUCTION}

Glioblastoma multiforme (GBM) is the most malignant tumor of the central nervous system and is characterized by rapid development, poor prognosis, problematic control, and high mortality among the patients (Krex et al., 2007; Okonogi et al., 2015); consequently, this cancer cannot be cured by traditional treatments. In recent decades, in contrast to many other cancers, the prognosis of GBM, especially high-grade GBM, showed only small improvements because of the limited response of GBM to standard treatments (Curran et al., 1993; Holland, 2000; Bleeker et al., 2012). Nevertheless, in recent years, computational biology and bioinformatics have provided new insights into the molecular pathogenesis of GBM and uncovered several possible biomarkers (Fujita et al., 2008; Verhaak et al., 2010; Preusser et al., 2011).

It has been suggested that genetic alterations and deregulation of metabolic or signaling pathways represent the major mechanism underlying the transformation of healthy cells into cancerous ones (Grzmil et al., 2011; Vogelstein et al., 2013). Various studies have focused on transcript profiling to identify genetic alterations between a tumor and healthy tissue or among tumor subtypes (stages). Godard et al. (2003) showed that 2 angiogenesisrelated factors, IGFBP2 and VEGF, are involved in specific biological functions and can be used for effective classification of tumors. Rich et al. (2005) reported that 3 key genes (SPARC, Doublecortex, and SEMA3B), which regulate cellular motility, may contribute to the poor prognosis in older patients with glioblastoma. The genome-scale high-throughput technology for transcript profiling holds promise as a clinical tool and may identify specific gene expression signatures and differential pathway activation at different tumor stages. Secondary utilization of the existing transcript data facilitates the discovery of possible biomarkers in high-grade GBM.

In this study, to further explore the pathogenesis and to improve the prognosis of highgrade GBM, we identified some relevant dysregulated genes and pathways by integrating several microarray datasets with a coexpression network. Furthermore, hub genes were identified by centrality analysis of the coexpression network. Finally, reverse-transcription PCR (RT-PCR) and western blotting were performed to validate the bioinformatic results. Thus, this study may shed light on the molecular events behind the development and progression of GBM. 


\section{MATERIAL AND METHODS}

\section{Bioinformatics}

\section{Data collection and preprocessing}

We conducted a search for transcription profiling data comparing samples from healthy subjects and patients with GBM. Three microarray datasets (deposited in ArrayExpress http://www.ebi.ac.uk/arrayexpress/) were selected: E-GEOD-15824 (Grzmil et al., 2011), E-MEXP-567 (Margareto et al., 2007), and E-MTAB-3073 (Madhavan et al., 2009). From these 3 datasets, 259 GBM samples and 33 control samples were included in the present study, and 155 of $259 \mathrm{GBM}$ patients had grade IV cancer. The characteristics of these 3 datasets are shown in Table 1.

Table 1. Characteristics of the previous studies included in the present study.

\begin{tabular}{l|c|c|l}
\hline Accession No. & Year & GBM sample size & \multirow{2}{*}{ Platform } \\
\cline { 3 - 4 } & & Total(Grade IV/Other grade/Controls) & \\
\hline E-GEOD-15824 & 2011 & $27(15 / 10 / 2)$ & Affymetrix HG-U133Plus2 \\
\hline E-MEXP-567 & 2007 & $9(6 / 0 / 3)$ & Affymetrix HG-U133A_2 \\
\hline E-MTAB-3073 & 2009 & $256(134 / 94 / 28)$ & Affymetrix HG-U133Plus2 \\
\hline
\end{tabular}

For each dataset, the annotations for probes were obtained from the manufacturer documentation, and the original information on all conditions was subjected to data preprocessing. First, the robust multichip average (RMA) method (Ma et al., 2006) and the quantile algorithm (Rifai and Ridker, 2001) were used for background correction and normalization. Next, the microarray suite 5.0 (MAS 5.0) algorithm (Pepper et al., 2007) was used to revise the perfect match and mismatch values that were selected by the median polish method. Then, the data were screened by the feature filter method. Each probe was mapped to 1 gene, and a probe was discarded if it did not match any gene.

\section{Detection of differentially expressed genes (DEGs)}

Different studies often involve experiments based on different plans, platforms, and methodologies; this situation hinders further analysis and leads to incorrect conclusions (Leek et al., 2010). Prior to detecting DEGs, we should first eliminate the undesirable effects from various batches of gene expression values. In the present work, distance-weighted discrimination (DWD) (Huang et al., 2012), an adaptation of support vector machines (Vapnik, 1995), was implemented to remove biases and to merge these 3 datasets into one.

In the present study, DEGs were identified by the empirical Bayesian method (F test) that is implemented in the linear models for microarray data (LIMMA) package and is adjusted by the false discovery rate (FDR) method (Wettenhall and Smyth, 2004). We used probe sets with an adjusted $\mathrm{P}$ value $<0.05$ and $\left|\log _{2} \mathrm{FC}\right| \geq 1.5$ (where $\mathrm{FC}=$ fold change).

\section{Coexpression network and module mining}

Construction of a coexpression network from high-throughput data has become a popular approach to analysis of the whole spectrum of pairwise relations among genes. In our 
study, differentially coexpressed gene pairs were identified by the empirical Bayesian (EB) approach. Details of the protocol are described elsewhere (Dawson and Kendziorski, 2012). A coexpressed gene pair with an FDR value less than 0.05 was assumed to be differentially coexpressed. When examining the microarray data that we included into the study, we found the expression data on grade IV GBM to be overwhelming. Thus, in this study, the coexpression network was constructed from expression data on grade IV GBM.

To extract functional modules from global coexpression networks, clustering analysis was implemented to detect highly connected subgraphs by means of the molecular complex detection (MCODE) algorithm (Bader and Hogue, 2003). In the present study, we used the following settings in MCODE for the detection of modules in a coexpression network: degree cutoff $=2, \mathrm{~K}$-core $=3$, and max. depth $=100$.

\section{Centrality analysis}

In any network structure, the role of a node depends not only on the features of the node itself but also on the topological structure of the network and on the features of other nodes. Thus, centrality analysis was performed to identify the nodes that are more sensitive to deletion or addition of a particular node to the network (Scardoni and Laudanna, 2012). Similar to a real network, a biological network is also scale-free: this characteristic strongly correlates with network robustness. In a scale-free network, the degree distribution of nodes follows a power law. Nodes with a high degree (highly connected) are often called "hubs", which interact with several other genes. Thus, the high degree of connectivity is suggestive of a central role in the interaction network. In this study, genes with degree $>30$ were considered hub genes.

\section{Validation of hub genes}

\section{Patients}

A total of 10 GBM samples were excised from patients who underwent a surgical procedure in our hospital between January 2014 and December 2014. The study population included 6 males and 4 females, ranging in age from 22 to 53 years (average, 22.4 years). In terms of the location of the tumors, there were 2 tumors in the temporal lobe, 2 in the frontal lobe, 2 in the basal ganglia region, 2 in the cerebellum, 1 in the occipital lobe, and 1 in the optic tract. Seven of the tumors had clear boundaries and a diameter of 1.5-8.6 cm. Clinical signs pointed to epilepsy, intracranial hypertension (headache, nausea, or vomiting), or a partial neural function defect. Written informed consent was obtained from the people who agreed to participate in this study before the collection of tissue samples. The study protocol was approved by the Institutional Ethical Committee and Review Board of Mudanjiang City Second People's Hospital.

\section{RT-PCR}

Total RNA was isolated from the tumor samples using the TRIzol Reagent (Invitrogen, Carlsbad, CA, USA) following the manufacturer protocol. cDNA was synthesized with the AMV reverse transcriptase and oligo $\left(\mathrm{dT}_{18}\right)$ primers (Invitrogen). The data were normalized to $\beta$-actin (reference gene). The primers for hub genes and $\beta$-actin are listed in Table 2. 
Table 2. The primer sequences and length for the candidate genes.

\begin{tabular}{|c|c|c|}
\hline Gene & Primer & Length (bp) \\
\hline \multirow[t]{2}{*}{ TFDP1 } & F: CAAGTGACCTGACCAACGGT & \multirow[t]{2}{*}{546} \\
\hline & R: GCAAATAAGCGGCATCAGGG & \\
\hline \multirow[t]{2}{*}{ CX3CR1 } & F: TGCATTTGCTGGGGAGAAGT & \multirow[t]{2}{*}{188} \\
\hline & R: AGAGAAGGAGGGACGCATCT & \\
\hline \multirow[t]{2}{*}{ GNG12 } & F: CAGCGAGATGGCTCAGTAGG & \multirow[t]{2}{*}{437} \\
\hline & R: GTGCCTGGTCCTAAGTCACC & \\
\hline \multirow[t]{2}{*}{ FCGBP } & F: TCCCTGTCCAAGATTGTGGC & \multirow[t]{2}{*}{825} \\
\hline & R: CCCAGAAAAGCGGTAGAGCA & \\
\hline \multirow[t]{2}{*}{ JAM2 } & F: TCTGAGCAAGGCCAAAACCT & \multirow[t]{2}{*}{364} \\
\hline & R: ATGTTGAGATCATTTGCATTCGT & \\
\hline \multirow[t]{2}{*}{ CD163 } & F: GGGGACATTCCCTGTTCTGG & \multirow[t]{2}{*}{717} \\
\hline & R: CAGGCGAAGTTGACCACTCT & \\
\hline \multirow[t]{2}{*}{$\mathrm{C} 3$} & F: GTTCATTCAGGGCACCGGACA & \multirow[t]{2}{*}{280} \\
\hline & R: CGGCATTCTGCACGCTTCAA & \\
\hline \multirow[t]{2}{*}{ LMO2 } & F: GAAAGGAAGAGCCTGGACCC & \multirow[t]{2}{*}{301} \\
\hline & R: TCTCATAGGCACGAATCCGC & \\
\hline \multirow[t]{2}{*}{ LAPTM4B } & F: AGCGAGGATGTCCTTGACAC & \multirow[t]{2}{*}{585} \\
\hline & R: TCTGGCCGTTCGTGTAACTC & \\
\hline \multirow[t]{2}{*}{$\beta$-actin } & F: AAGTACTCCGTGTGGATCGG & \multirow[t]{2}{*}{615} \\
\hline & R: TCAAGTTGGGGGACAAAAAG & \\
\hline
\end{tabular}

Amplification of the reverse-transcribed RNA was performed in a total volume of 20 $\mu \mathrm{L}$ containing $2 \mu \mathrm{L}$ diluted cDNA, $8 \mu \mathrm{L}$ dNTPs, $1 \mu \mathrm{L}$ High Fidelity Taq DNA Polymerase (Invitrogen), and $3 \mu \mathrm{L}$ each forward and reverse primer. The PCR cycling conditions for the candidate genes were as follows: $94^{\circ} \mathrm{C}$ for $2 \mathrm{~min} ; 30$ cycles of $98^{\circ} \mathrm{C}$ for $10 \mathrm{~s}, 54^{\circ} \mathrm{C}$ for $15 \mathrm{~s}$, and $68^{\circ} \mathrm{C}$ for $1 \mathrm{~min}$; and final extension at $72^{\circ} \mathrm{C}$ for $7 \mathrm{~min}$. Each reaction was performed in triplicate. The RT-PCR products were separated on $1.5 \%$ agarose gels and then analyzed with the Quantity One software (Bio-Rad, Hercules, CA, USA).

\section{Western blotting}

All brain tissue samples were ground to a powder in liquid nitrogen and then incubated with lysis buffer [62.5 mM Tris-HCl (pH 6.8), 10\% glycerol, and $2 \%$ sodium dodecyl sulfate (SDS)] on ice. Protein concentration was determined by the Bradford assay (Bio-Rad). Ten micrograms of total protein was separated by electrophoresis on a $12 \%$ SDS-polyacrylamide gel and electrotransferred onto a polyvinylidene fluoride membrane. The membrane was incubated with fresh blocking buffer (containing 5\% nonfat dry milk in Tris-buffered saline) at room temperature for $2 \mathrm{~h}$ and was then incubated with a rabbit anti-human IgG antibody (1:10,000 dilution; Sigma-Aldrich, St. Louis, MO, USA) at $37^{\circ} \mathrm{C}$ for $2 \mathrm{~h}$. The membrane was rinsed 3 times for 5 min each in Tris-buffered saline containing Tween 20. After that, the membrane was incubated with a horseradish peroxidase-conjugated goat anti-rabbit IgG antibody (1:5000; Amersham Pharmacia Biotech, Little Chalfont, Buckinghamshire, UK) at room temperature for $2 \mathrm{~h}$. Enhanced chemiluminescence was used for detection. Immunoreactive bands were scanned and quantified by means of the Scion Image software (Scion, Frederick, MD, USA). GAPDH served as a loading control.

\section{Data analysis}

All data are reported as means $\pm \mathrm{SD}$, and statistical analysis was carried out with the SPSS 19.0 software (SPSS, Chicago, IL, USA). The Student $t$-test was used for assessment 
of the significance of differences. A difference with $\mathrm{P}<0.05$ was considered statistically significant.

\section{RESULTS}

\section{DEGs in GBM}

After preprocessing of the 3 abovementioned expression profiles, the numbers of genes in E-GEOD-15824, E-MEXP-567, and E-MTAB-3073 were as follows: 20,109; 12,493; and 20,109, respectively. After merging of the 3 datasets by the DWD method, we screened 4214 genes. In accordance with the criteria FDR $<0.05$ and $\left|\log _{2} \mathrm{FC}\right| \geq 1.5$, a total of 277 genes were consistently differentially expressed in GBM, including 102 upregulated genes and 175 downregulated genes. Pathway enrichment analysis showed that these DEGs were most significantly enriched in the cell cycle pathway $(\mathrm{P}=0.02)$.

\section{Coexpression network and modules}

The coexpression network of DEGs was constructed by means of the EB algorithm, and the coexpression relations within coexpressed gene pairs were deduced from the gene expression data on grade IV GBM. A total of 1005 coexpressed gene pairs with FDR $\leq 0.05$ were identified. Finally, the coexpression network with 232 nodes was built in the Cytoscape software, as shown in Figure 1. The MCODE algorithm was implemented to extract modules. By clustering, we identified 7 modules. Among them, Modules 1, 2, and 3 showed the highest module scores. The characteristics of the modules identified in our study are shown in Table 3.

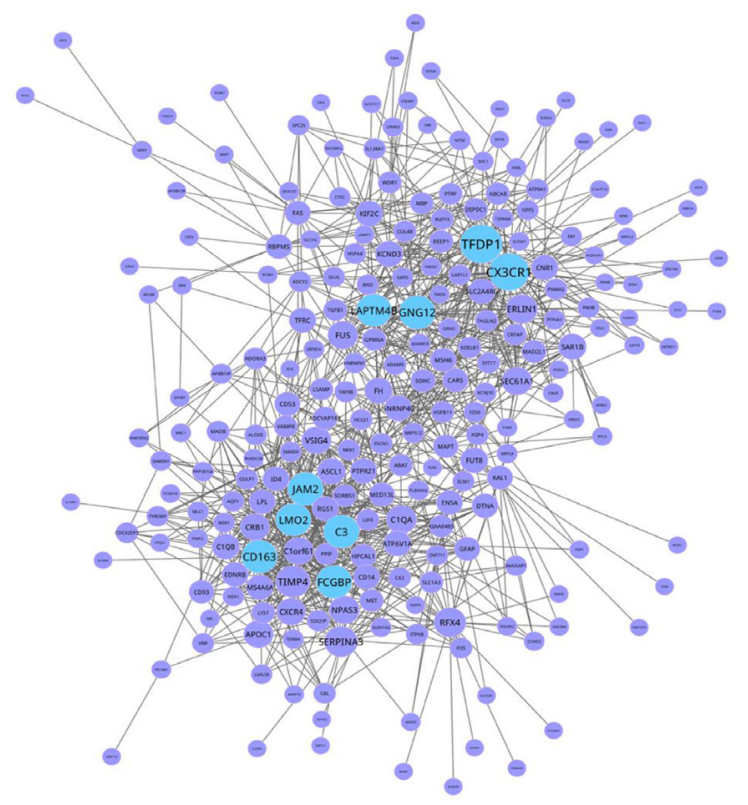

Figure 1. Coexpression network of high-grade glioblastoma multiforme on the basis of differentially expressed genes. Nodes represent genes and edges represent the interactions. The blue nodes are hub genes. 
Table 3. Characteristics of modules identified in this study.

\begin{tabular}{|c|c|c|c|c|}
\hline Module & Score & Nodes & Edges & Genes at the top $10 \%$ of degree distribution \\
\hline 1 & 9.771 & 36 & 171 & $\begin{array}{l}\text { CD163, FCGBP, JAM2, TIMP4, C1orf } 61, \text { CXCR4, C1QA, NPAS3, APOC1, } \\
\text { VSIG4 }\end{array}$ \\
\hline 2 & 8.000 & 60 & 236 & $\begin{array}{l}\text { FCGBP, JAM2, GNG12, TIMP4, C1orf61, CXCR4, C1QA, NPAS3, } \\
\text { CD163, SERPINA3, CRB1, ERLIN1 }\end{array}$ \\
\hline 3 & 7.848 & 67 & 259 & CD163, LMO2, JAM2, Clorf61, C1OA, NPAS3, SERPINA3, CRB1, RFX4 \\
\hline 4 & 4.853 & 69 & 165 & LMO2, JAM2, C1QA, SERPINA3, CRB1, RFX4 \\
\hline 5 & 3.474 & 39 & 66 & LMO2, SERPINA3, RFX4, CRB1 \\
\hline 6 & 3.463 & 42 & 71 & GNG12, ERLIN1 \\
\hline 7 & 2.143 & 15 & 15 & LMO2 \\
\hline
\end{tabular}

The bold genes are hub genes.

\section{Network analysis}

Centrality analysis was performed to study topological characteristics of the coexpression network of GBM (Figure 2). By analyzing the degree distribution, we labeled 9 genes as hub genes (their connectivity degree was greater than the threshold value 30 ). The TFDP1 gene showed the highest degree (43) in the network, followed by $C X 3 C R 1$, GNG12, FCGBP, JAM2, CD163, C3, LMO2, and LAPTM4B. Of the 9 hub genes, 3 genes were upregulated and 6 were downregulated. The details are shown in Table 4.
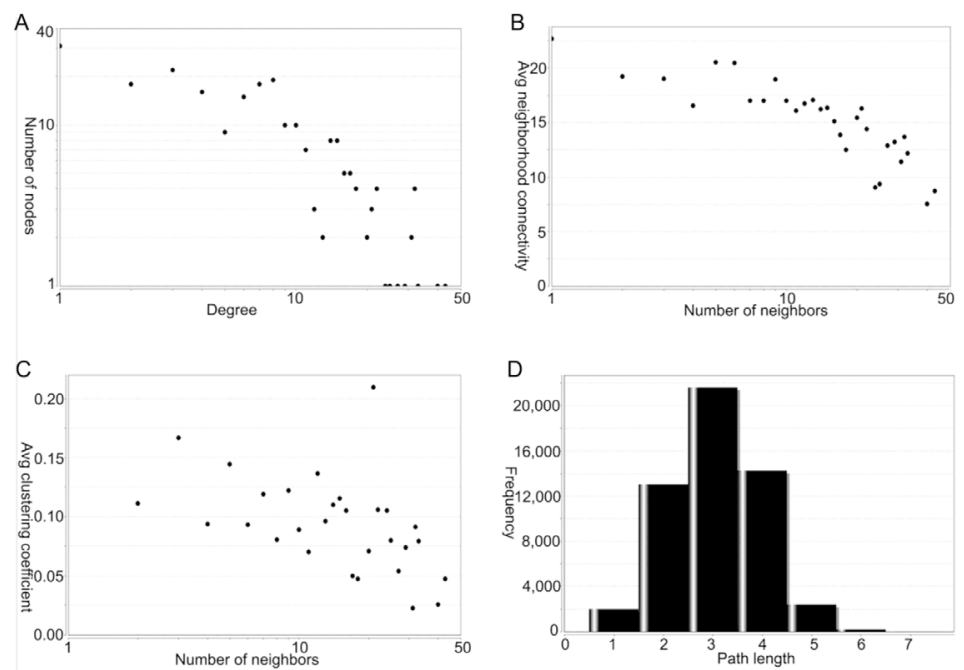

Figure 2. Topological characteristics of the coexpression network according to centrality analysis.

Table 4. Fold change and degree distribution of hub genes in our study.

\begin{tabular}{l|l|c|c}
\hline Gene & Description & Degree & Log2FC \\
\hline TFDP1 & Transcription factor Dp-1 & 43 & 1.57 \\
\hline$C X 3 C R 1$ & Chemokine (C-X3-C motif) receptor 1 & 40 & -1.85 \\
\hline$G N G 12$ & Guanine nucleotide binding protein (G protein), gamma 12 & 33 & 1.77 \\
\hline FCGBP & Fc fragment of IgG binding protein; & 32 & -1.80 \\
\hline$J A M 2$ & Junctional adhesion molecule 2 & 32 & -1.55 \\
\hline$C D 163$ & CD163 molecule & 32 & -2.22 \\
\hline$C 3$ & Complement component 3 & 32 & -1.76 \\
\hline LMO2 & LIM domain only 2 & 31 & -2.00 \\
\hline LAPTM4B & Lysosomal protein transmembrane 4 beta & 31 & 1.81 \\
\hline
\end{tabular}




\section{Validation of the hub genes}

In this study, RT-PCR and western blotting were conducted to analyze the mRNA and protein expression, respectively, in the brain tissues of patients with GBM. The GBM tumor samples showed higher levels of mRNA and protein expression of TFDP1, GNG12, and LAPTM4B in comparison with healthy controls $(\mathrm{P}<0.05)$. CX3CR1, FCGBP, CD163, $\mathrm{C} 3$, and LMO2 were downregulated in GBM as compared to healthy controls at both mRNA and protein levels $(\mathrm{P}<0.05$, Figure $3 \mathrm{~A})$; these results were consistent with our bioinformatics analysis. In contrast, mRNA and protein expression levels of JAM2 showed no significant differences between the 2 groups $(\mathrm{P}>0.05$, Figure $3 \mathrm{~B})$, but this gene was downregulated in GBM tissues according to our bioinformatics analysis.
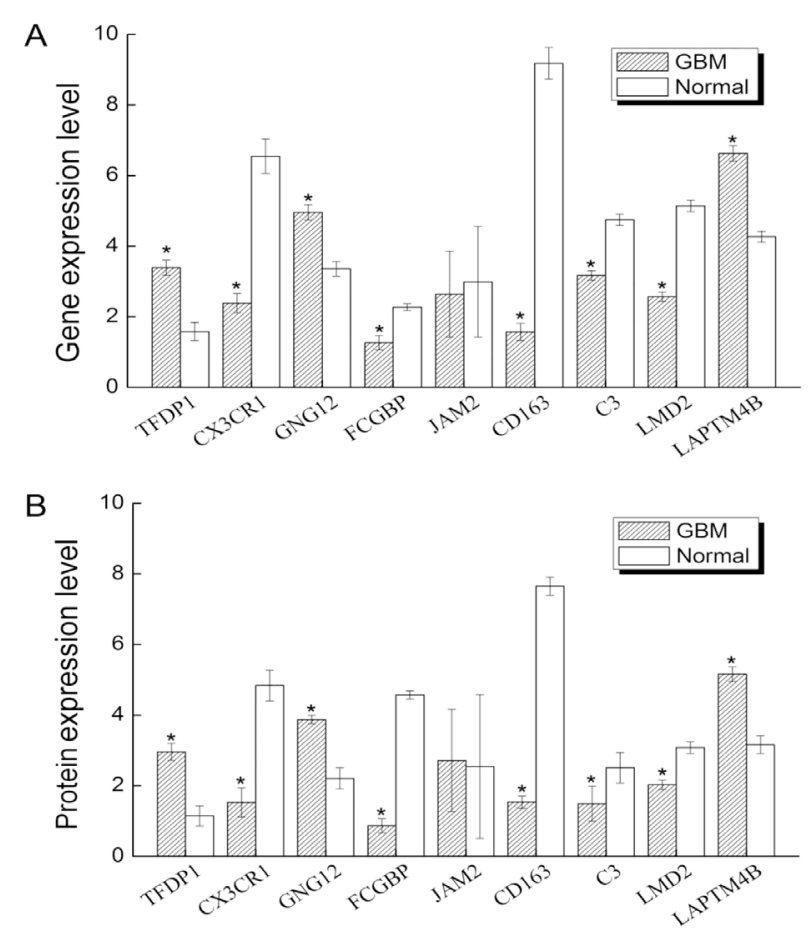

Figure 3. Relative expression levels of hub genes in patients with glioblastoma multiforme (GBM). A. mRNA levels. B. Protein expression levels. $* \mathrm{P}<0.05$.

\section{DISCUSSION}

GBM is a complex disease whose pathogenesis has not been fully elucidated. Identification of the key genes associated with GBM should elucidate the pathogenesis and point to therapeutic targets in GBM. In the present study, 277 DEGs were found to be associated with GBM. Among these disturbed genes, we identified 9 hub genes (those with a high degree of connectivity). Furthermore, experimental validation of these genes mostly supported our bioinformatic results (except for JAM2 at both the mRNA and protein levels). The probable reasons for the inconsistent result may be, for example, race, variations in other 
compounding factors and experimental conditions, and the small sample size. The criteria for differential expression in our bioinformatics analysis were FDR $<0.05$ and $\left|\log _{2} \mathrm{FC}\right| \geq 1.5$; the Student $t$-test was used for the validation part of the project. The microarray data were obtained from the ArrayExpress database (not generated by us). In addition, the small number of samples in the experimental groups may be another significant reason.

In this work, the gene TFDP1 was found to be upregulated and showed the highest degree of connectivity according to our network analysis strategy. As an important transcription factor, TFDP1 has been shown to interact with several oncogenes, such as E2F (Hsu et al., 2001) and P53 (Sørensen et al., 1996). In vivo, TFDP1 interacts with E2F family proteins, forming heterodimers. The E2F-TFDP1 transcription factor can regulate some cell cycle (S phase)-related genes, which perform essential functions in cellular processes (Zhang et al., 1997). Moreover, several studies showed that the E2F-TFDP1 transcription factor is involved in dysregulation of the cell cycle in certain cancers (Girling et al., 1993; Matsumoto et al., 1997; Williams et al., 1997). We found the cell cycle pathway to be significantly enriched in our set of GBM-related genes; TFDP1 is known to participate in this pathway. These findings point to a possible important role of TFDP1 in the development and progression of GBM. Our study seems to be the first to show that TFDP1 is associated with high-grade GBM.

The cell cycle is a series of events that take place in a cell that lead to cell division and duplication. Dysregulation of cell cycle components may cause the cell to multiply uncontrollably, thus leading to tumor formation (Champeris Tsaniras et al., 2014), as is the case for GBM (Hazane-Puch et al., 2015; Xie et al., 2015). Various studies have shown that the cell cycle pathway and cell cycle-related molecules can be considered therapeutic targets of many cancers (Rao, 1996; Newman et al., 2002). Di Tomaso et al. (2000) found that the uncontrolled proliferation of glioma cells may be linked to genetic alterations in the cell cycle pathway. Moreover, Li et al. (2014) uncovered several inverted gene pairs that participate in the cell cycle pathway and may help to develop new treatments of GBM.

In conclusion, in this study, by integrating microarray expression data with a coexpression network, we identified 9 hub genes and 7 modules. Our hub gene TFDP 1 and the cell cycle pathway were found to be strongly associated with high-grade GBM. This finding may yield new clues to the molecular pathogenesis of GBM. Further research (clinical and basic) is expected to elucidate the specific mechanisms of action of TFDP1 and of the cell cycle pathway in relation to GBM.

\section{Conflicts of interest}

The authors declare no conflict of interest.

\section{ACKNOWLEDGMENTS}

We thank Dr. Wen Sun for helpful discussion and critical reading of the manuscript and $\mathrm{Xin} \mathrm{Yu,} \mathrm{Juan} \mathrm{Yin,} \mathrm{and} \mathrm{Hai-Yan} \mathrm{Yang} \mathrm{for} \mathrm{technical} \mathrm{assistance.}$

\section{REFERENCES}

Bader GD and Hogue CW (2003). An automated method for finding molecular complexes in large protein interaction networks. BMC Bioinformatics 4: 2. http://dx.doi.org/10.1186/1471-2105-4-2 
Bleeker FE, Molenaar RJ and Leenstra S (2012). Recent advances in the molecular understanding of glioblastoma. $J$. Neurooncol. 108: 11-27. http://dx.doi.org/10.1007/s11060-011-0793-0

Champeris Tsaniras S, Kanellakis N, Symeonidou IE, Nikolopoulou P, et al. (2014). Licensing of DNA replication, cancer, pluripotency and differentiation: an interlinked world? Semin. Cell Dev. Biol. 30: 174-180. http://dx.doi. org/10.1016/j.semcdb.2014.03.013

Curran WJ, Jr., Scott CB, Horton J, Nelson JS, et al. (1993). Recursive partitioning analysis of prognostic factors in three Radiation Therapy Oncology Group malignant glioma trials. J. Natl. Cancer Inst. 85: 704-710. http://dx.doi. org/10.1093/jnci/85.9.704

Dawson JA and Kendziorski C (2012). An empirical Bayesian approach for identifying differential coexpression in highthroughput experiments. Biometrics 68: 455-465. http://dx.doi.org/10.1111/j.1541-0420.2011.01688.x

Di Tomaso E, Pang JC, Lam HK, Tian XX, et al. (2000). Establishment and characterization of a human cell line from paediatric cerebellar glioblastoma multiforme. Neuropathol. Appl. Neurobiol. 26: 22-30. http://dx.doi.org/10.1046/ j.1365-2990.2000.00214.x

Fujita A, Sato JR, Festa F, Gomes LR, et al. (2008). Identification of COL6A1 as a differentially expressed gene in human astrocytomas. Genet. Mol. Res. 7: 371-378. http://dx.doi.org/10.4238/vol7-2gmr432

Girling R, Partridge JF, Bandara LR, Burden N, et al. (1993). A new component of the transcription factor DRTF1/E2F. Nature 365: 83-87. http://dx.doi.org/10.1038/365468d0

Godard S, Getz G, Delorenzi M, Farmer P, et al. (2003). Classification of human astrocytic gliomas on the basis of gene expression: a correlated group of genes with angiogenic activity emerges as a strong predictor of subtypes. Cancer Res. 63: 6613-6625.

Grzmil M, Morin P, Jr., Lino MM, Merlo A, et al. (2011). MAP kinase-interacting kinase 1 regulates SMAD2-dependent TGF- $\beta$ signaling pathway in human glioblastoma. Cancer Res. 71: 2392-2402. http://dx.doi.org/10.1158/0008-5472. CAN-10-3112

Hazane-Puch F, Arnaud J, Trocmé C, Faure P, et al. (2015). Sodium selenite decreased HDAC activity, cell proliferation and induced apoptosis in three human glioblastoma cells. Anticancer. Agents Med. Chem. http://dx.doi.org/10.2174 1871520615666150819095426.

Holland EC (2000). Glioblastoma multiforme: the terminator. Proc. Natl. Acad. Sci. USA 97: 6242-6244. http://dx.doi. org/10.1073/pnas.97.12.6242

Hsu SI, Yang CM, Sim KG, Hentschel DM, et al. (2001). TRIP-Br: a novel family of PHD zinc finger- and bromodomaininteracting proteins that regulate the transcriptional activity of E2F-1/DP-1. EMBO J. 20: 2273-2285. http://dx.doi. org $/ 10.1093 / \mathrm{emboj} / 20.9 .2273$

Huang H, Lu X, Liu Y, Haaland P, et al. (2012). R/DWD: distance-weighted discrimination for classification, visualization and batch adjustment. Bioinformatics 28: 1182-1183. http://dx.doi.org/10.1093/bioinformatics/bts096

Krex D, Klink B, Hartmann C, von Deimling A, et al.; German Glioma Network (2007). Long-term survival with glioblastoma multiforme. Brain 130: 2596-2606. http://dx.doi.org/10.1093/brain/awm204

Leek JT, Scharpf RB, Bravo HC, Simcha D, et al. (2010). Tackling the widespread and critical impact of batch effects in high-throughput data. Nat. Rev. Genet. 11: 733-739. http://dx.doi.org/10.1038/nrg2825

Li W, Li K, Zhao L and Zou H (2014). Bioinformatics analysis reveals disturbance mechanism of MAPK signaling pathway and cell cycle in Glioblastoma multiforme. Gene 547: 346-350. http://dx.doi.org/10.1016/j.gene.2014.06.042

Ma L, Robinson LN and Towle HC (2006). ChREBP*Mlx is the principal mediator of glucose-induced gene expression in the liver. J. Biol. Chem. 281: 28721-28730. http://dx.doi.org/10.1074/jbc.M601576200

Madhavan S, Zenklusen JC, Kotliarov Y, Sahni H, et al. (2009). Rembrandt: helping personalized medicine become a reality through integrative translational research. Mol. Cancer Res. 7: 157-167. http://dx.doi.org/10.1158/1541-7786. MCR-08-0435

Margareto J, Leis O, Larrarte E, Idoate MA, et al. (2007). Gene expression profiling of human gliomas reveals differences between GBM and LGA related to energy metabolism and notch signaling pathways. J. Mol. Neurosci. 32: 53-63. http://dx.doi.org/10.1007/s12031-007-0008-5

Matsumoto H, Wang X, Takahashi A and Ohnishi T (1997). Induction of cdk2 after gamma-ray irradiation is dependent on p53 status. Int. J. Oncol. 10: 1257-1260.

Newman DJ, Cragg GM, Holbeck S and Sausville EA (2002). Natural products and derivatives as leads to cell cycle pathway targets in cancer chemotherapy. Curr. Cancer Drug Targets 2: 279-308. http://dx.doi.org/10.2174/1568009023333791

Okonogi N, Shirai K, Oike T, Murata K, et al. (2015). Topics in chemotherapy, molecular-targeted therapy, and immunotherapy for newly-diagnosed glioblastoma multiforme. Anticancer Res. 35: 1229-1235.

Pepper SD, Saunders EK, Edwards LE, Wilson CL, et al. (2007). The utility of MAS5 expression summary and detection call algorithms. BMC Bioinformatics 8: 273. http://dx.doi.org/10.1186/1471-2105-8-273

Genetics and Molecular Research 15 (2): gmr.15027646

CFUNPEC-RP www.funpecrp.com.br 
Hub genes and pathways in high-grade glioblastoma multiforme

Preusser M, de Ribaupierre S, Wöhrer A, Erridge SC, et al. (2011). Current concepts and management of glioblastoma. Ann. Neurol. 70: 9-21. http://dx.doi.org/10.1002/ana.22425

Rao RN (1996). Targets for cancer therapy in the cell cycle pathway. Curr. Opin. Oncol. 8: 516-524. http://dx.doi. org/10.1097/00001622-199611000-00012

Rich JN, Hans C, Jones B, Iversen ES, et al. (2005). Gene expression profiling and genetic markers in glioblastoma survival. Cancer Res. 65: 4051-4058. http://dx.doi.org/10.1158/0008-5472.CAN-04-3936

Rifai N and Ridker PM (2001). Proposed cardiovascular risk assessment algorithm using high-sensitivity C-reactive protein and lipid screening. Clin. Chem. 47: 28-30.

Scardoni G and Laudanna C (2012). Centralities based analysis of complex networks. In: New frontiers in graph theory (Zhang Y, eds.). InTech, Rijeka. 323-348.

Sørensen TS, Girling R, Lee CW, Gannon J, et al. (1996). Functional interaction between DP-1 and p53. Mol. Cell. Biol. 16: 5888-5895. http://dx.doi.org/10.1128/MCB.16.10.5888

Vapnik VN (1995). The nature of statistical learning theory (1st). Springer-Verlag, New York.

Verhaak RG, Hoadley KA, Purdom E, Wang V, et al.; Cancer Genome Atlas Research Network (2010). Integrated genomic analysis identifies clinically relevant subtypes of glioblastoma characterized by abnormalities in PDGFRA, IDH1, EGFR, and NF1. Cancer Cell 17: 98-110. http://dx.doi.org/10.1016/j.ccr.2009.12.020

Vogelstein B, Papadopoulos N, Velculescu VE, Zhou S, et al. (2013). Cancer genome landscapes. Science 339: 15461558. http://dx.doi.org/10.1126/science. 1235122

Wettenhall JM and Smyth GK (2004). limmaGUI: a graphical user interface for linear modeling of microarray data. Bioinformatics 20: 3705-3706. http://dx.doi.org/10.1093/bioinformatics/bth449

Williams CD, Linch DC, Sørensen TS, La Thangue NB, et al. (1997). The predominant E2F complex in human primary haemopoietic cells and in AML blasts contains E2F-4, DP-1 and p130. Br. J. Haematol. 96: 688-696. http://dx.doi. org/10.1046/j.1365-2141.1997.d01-2086.X

Xie R, Zhang Y, Shen C, Cao X, et al. (2015). Knockdown of immature colon carcinoma transcript-1 inhibits proliferation of glioblastoma multiforme cells through Gap 2/mitotic phase arrest. Onco Targets Ther. 8: 1119-1127.

Zhang Y, Venkatraj VS, Fischer SG, Warburton D, et al. (1997). Genomic cloning and chromosomal assignment of the E2F dimerization partner TFDP gene family. Genomics 39: 95-98. http://dx.doi.org/10.1006/geno.1996.4473 